\title{
Efficacy of Neuro - Developmental Therapy Based Gait Training in Correction of Gait Pattern of Post Stroke Hemiparetic Patients
}

\author{
Vij $^{1}$, J.S. \& Multani ${ }^{2}$ N.K.
}

${ }^{2}$ Professor, Dept of Physiotherapy, Punjabi University, Patiala-147001, Punjab

\section{Abstract}

The purpose of the study is to compare the efficacy of Neuro- Developmental Therapy (NDT) based gait training with conventional physiotherapy in re-education of gait in post stroke hemiparetic patients. 24 post stroke hemiparetic subjects $(n=24$, males $=20$, females $=4)$ aged 40-70 yrs (mean age 56.13 yrs) affected for a period of 4-6 weeks and having ability to walk, with or without walking aid, were included in the study. All the subjects were assessed for step length, stride length, cadence, gait velocity and pressure areas in different parts of the foot using Harris mat. The quality of gait was assessed using Wisconsin Gait Scale (WGS). All the subjects were conveniently divided into two groups viz Group A and Group B. Group A received NDT based gait training along with conventional physiotherapy whereas Group B received only conventional physiotherapy for a total period of 8 weeks. After statistical analysis, a significant improvement was observed in step length affected $(t=6.82, t=4.25)$, step length unaffected $(\mathrm{t}=7.27, \mathrm{t}=4.78)$, stride length $(\mathrm{t}=7.63, \mathrm{t}=4.41)$, gait velocity $(\mathrm{t}=3.34$, $\mathrm{t}=4.69)$, cadence $(\mathrm{t}=4.56, \mathrm{t}=6.08)$ and WGS scores $(\mathrm{t}=6.44, \mathrm{t}=5.86)$ in both the groups. Whereas significant decrease in the spasticity (MAS-Hip, $\mathrm{t}=3.46$, MAS-Knee, $\mathrm{t}=3.73$, MASAnkle, $\mathrm{t}=3.73$ ) was only observed in the group receiving NDT based gait training along with conventional physiotherapy (Group A). However, no statistically significant difference was observed in the high and low pressure areas of upper, middle and lower parts of foot in both the groups after the intervention. In between comparison of the two groups showed a significant difference in the improvement in the step length of affected side $(t=3.94)$, step length of unaffected side $(t=4.31)$, stride length $(t=5.1)$ as well as WGS scores between the two groups. The present study has highlighted that both, the conventional physiotherapy as well as addition of NDT based gait training, are effective in improving the step length, stride length, cadence, velocity and WGS scores in post stroke hemiparetic patients. But in comparison to conventional physiotherapy alone, addition of NDT based gait training is more effective in improving step length, stride length, spasticity and WGS scores in these patients.

Key words: Stroke, Hemiparesis, NDT based gait training, Conventional physiotherapy, Harris mat

\section{Introduction}

Stroke is the leading cause of adult disability and inpatient rehabilitation admissions (AHA, 2003, DeJong et al, 2005). It is the most important single cause of disability in people living in their own home (Hankey, 1999). According to International Stroke trial reports, at 6 months after stroke, about $20 \%$ are dead,
$50 \%$ are independent and $30 \%$ are dependent in self care (Weir et al, 2001). An estimated $70 \%$ of the patients who survive a stroke are unable to walk independently during the first three to four weeks post stroke. Dependence in mobility is one of the primary reasons of admission for inpatient rehabilitation after stroke. Much effort goes into helping these patients regain the ability to walk at least in the home prior to discharge. In 
spite of these efforts, approximately $35 \%$ of survivors with initial paralysis of the leg do not regain useful walking function, and $25 \%$ of all survivors are unable to walk without full assistance (Akhan et al, 1995). Several studies show that most of the motor recovery following stroke occurs within the first 3 months poststroke and that the initially steep recovery curve levels at about 6 months to a year post-stroke (Skilbeck et al, 1983).

Stroke patients show various kinds of deficits in perception, muscle strength, motor control, passive mobility, sensation, tone and balance. These impairments have significant effects upon walking ability. Walking is possible for the majority of patients following stroke, but it is very rare that it returns to normal (Jorgenson et al, 1995). Although the reported figures vary, approximately 50$80 \%$ of patients who survive a stroke will eventually regain some degree of walking ability (Skilbeck et al, 1983). Nevertheless, outcome studies on rehabilitation of patients who are stroke survivors reveal that $93 \%$ of patients have difficulty in walking independently in the community after being discharged from hospital.

Thus, the ability to walk is the major factor that determines whether the patient will return to the previous level of activity or not, because independent ambulation is essential for community reintegration and social participation. Thus, gait training accounts for a large proportion of time spent in stroke rehabilitation. Gait correction and re-education, therefore, is an important physical therapy intervention for patients following stroke. Therefore, basic purpose of any rehabilitation process in stroke is to make the person ambulatory and thus reduce his disability. This apparently indicates that there is a dire need to analyze the gait patterns of these patients so as to formulate and then effectively execute the strategies to correct and re-educate it.

The walking patterns of both individuals without mobility problems (Winter et al, 1990) and patients with hemiplegia have been well documented (Olney \& Richards, 1996). The gait of people following stroke is characterized by problems with generating, timing, and grading of muscle activity, hypertonicity, and mechanical changes in soft tissues (Olney \& Richards, 1996). Gait speed, stride length, and cadence are lower than normal values (Olney \& Richards, 1996). Common kinematic deviations during the stance phase of the gait cycle are decreased peak hip extension angles, decreased lateral pelvic displacement, changed knee extension, and decreased plantar-flexion angles (Moseley et al, 1993). Common kinematic deviations during the swing phase of the gait cycle are decreased hip flexion, knee extension, and dorsiflexion (Moore et al, 1993). Kinetic characteristics and abnormal motion of the unaffected side have not been commonly documented in patients following stroke ((Olney \& Richards, 1996; Quervain et al, 1996).

Motor rehabilitation of adults with hemiplegia uses a number of physiotherapy approaches developed by authors such as Bobath, Rood, Kabat, Brunnstrom and Perfetti. The Bobath concept, also known as neurodevelopmental treatment, is a widely used approach in the rehabilitation of hemiparetic subjects in many countries. Despite 50 years of clinical use, its 
effectiveness is questionable (Paci, 2003). Till now, very few researches have been done exploring the efficacy of NDT in hemiparetic patients, particularly in gait correction and rehabilitation. Whatever studies have been done, they have been case reports comprising one or two subjects and do not clearly support NDT as an effective therapeutic procedure in gait rehabilitation.

Thus, most effective treatment strategies to use in gait re-education following stroke, seems to remain unknown (Ashburn et al, 1993). Given the popularity of NDT in treatment of adults with post-stroke hemiplegia, an overview of effective evidence for the NDT in rehabilitation of post- stroke hemiplegic patients is necessary in order to justify its wider use by physiotherapists. This study describes gait re-education based on the NDT concept, which is one of the leading treatment approaches in Europe for rehabilitation of patients with stroke. The primary aim of this study is to investigate the efficacy of NDT based gait training in improving both, the quantitative as well as qualitative gait parameters in post stroke hemiparetic patients.

\section{Materials and Methods}

Post stroke hemiparetic patients who were in stable condition and could walk, with or without gait aid, were recruited for this study. Patients who met the following entry criteria were included; (i) unilateral hemiplegia caused by cerebral hemisphere stroke other than trauma, brain tumor or secondary etiology; (ii) affected for a period of 4-6 weeks; (iii) good cooperation and compliance in gait analysis; (iv) ability to walk for more than $10 \mathrm{~m}$; (v) absence of cerebellar or brain stem strokes; (vi) lack of other peripheral or central nervous system dysfunction; (vii) having no more than one CVA prior to testing; (viii) absence of active inflammatory or pathological changes in the joints of the lower limbs, limb length discrepancy, or foot deformities (such as pes valgus, pes cavus, hallux valgus or hallux rigidus) in the previous 6 months; (ix) lack of severe visual spatial dysfunction; ( $x$ ) no active medical problems. The study was approved by the Institutional Ethical Committee of Punjabi University, Patiala. All patients received an explanation of the study and gave informed consent before enrolment. A total of 24 patients (20 males and 4 females), with an average age of 56.13 years (range 40-70 years), were included in this study.

The gait pattern was assessed within a week after the patient had resumed walking, which was defined as the ability to walk ten to fifteen meters. All the subjects were instructed to walk along a smooth, horizontal $10 \mathrm{~m}$ - long walkway at a comfortable speed. Only the middle five steps were evaluated to avoid the variable steps associated with initiation and termination of gait. The gait velocity, step length, stride length, cadence and foot pressure areas were measured for quantitative gait analysis.

The step length $(\mathrm{cm})$ was measured from the geometrical heel centre of the current footprint to the same of the previous footprint on the opposite foot, and the stride length $(\mathrm{cm})$ from the line of progression between the heel points of two consecutive footprints of the same foot. The walking velocity $(\mathrm{cm} / \mathrm{s})$ was obtained after dividing the recorded distance by the ambulation time. The cadence was calculated by asking the patient to walk for one minute through a straight pathway with self-selected speed 
and then calculating the number of steps taken during one minute. The areas of low and high pressure (in upper, middle and lower part of foot) were determined using foot imprints on Harrison mat. Each foot imprint was divided into three parts upper part, middle part and lower part. The Wisconsin Gait Scale (WGS) was used for qualitative gait analysis and modified Ashworth scale for assessing the spasticity in specific muscle groups.

All the subjects were conveniently divided into two groups - Group A and Group B. Group A received NDT based gait training along with conventional physiotherapy whereas Group B received only conventional physiotherapy.
Each patient was given a physiotherapy program of 8 weeks duration, with 5 physiotherapy sessions per week, each therapy session lasting for about 40 minutes. All the subjects were reassessed for the above parameters again after the completion of 8 weeks of intervention.

\section{Statistical analysis}

A paired t-test was performed to analyze the difference between the various gait variables in both the groups after the intervention. An independent ttest was performed to analyze the difference in the changes in these gait variables in between the two groups.

\section{Results}

Table 1.Mean scores and improvement of the gait parameters in the two groups

\begin{tabular}{|c|c|c|c|c|c|c|c|c|}
\hline \multirow[b]{2}{*}{ Parameters } & \multicolumn{4}{|c|}{$\begin{array}{c}\text { Group A (NDT and Conventional } \\
\text { Physiotherapy) }\end{array}$} & \multicolumn{4}{|c|}{ Group B (Conventional Physiotherapy) } \\
\hline & $\begin{array}{l}\text { Mean } \\
\text { (Before) }\end{array}$ & $\begin{array}{l}\text { Mean } \\
\text { (After) }\end{array}$ & $\begin{array}{l}\mathrm{t}- \\
\text { value }\end{array}$ & p-value & $\begin{array}{l}\text { Mean } \\
\text { (Before) }\end{array}$ & $\begin{array}{l}\text { Mean } \\
\text { (After) }\end{array}$ & $\begin{array}{l}t- \\
\text { value }\end{array}$ & p-value \\
\hline $\begin{array}{l}\text { Step length affected } \\
(\mathrm{cms})\end{array}$ & 27.36 & 37.82 & 6.82 & $<0.0001$ & 18.45 & 22 & 4.25 & $=0.0017$ \\
\hline $\begin{array}{l}\text { Step length unaffected } \\
\text { (cms) }\end{array}$ & 18.27 & 32.36 & 7.27 & $<0.0001$ & 10.09 & 14.91 & 4.78 & $=\mathbf{0 . 0 0 0 7}$ \\
\hline Stride length (cms) & 46 & 70.18 & 7.63 & $<0.0001$ & 28.55 & 35.36 & 4.41 & $=0.0013$ \\
\hline Cadence & 53.26 & 73.45 & 4.56 & $=0.0010$ & 50.36 & 62.55 & 6.08 & $=0.0001$ \\
\hline Gait velocity $(\mathrm{cm} / \mathrm{s})$ & 25.03 & 35.57 & 3.34 & $=0.0075$ & 21.37 & 26.83 & 4.69 & $=0.0009$ \\
\hline MAS Score - Hip & 0.82 & 0.27 & 3.46 & $=0.0061$ & 0.73 & 0.55 & 1.49 & $=0.1669$ \\
\hline MAS Score - Knee & 1.36 & 0.64 & 3.73 & $=0.0039$ & 1.36 & 1.18 & 1.49 & $=0.1669$ \\
\hline MAS Score - Ankle & 1.64 & 0.91 & 3.73 & $=0.0039$ & 1.73 & 1.55 & 1.49 & $=0.1669$ \\
\hline WGS Score & 28.90 & 20.52 & 6.44 & $<0.0001$ & 29.69 & 26.75 & 5.86 & $=0.0002$ \\
\hline $\begin{array}{l}\text { Low pressure area - } \\
\text { Upper part }(\%)\end{array}$ & 43.52 & 37.47 & 2.21 & $\begin{array}{l}=0.0518 \\
(\mathrm{NS})\end{array}$ & 49.77 & 39.26 & 1.74 & $\begin{array}{l}=0.1130 \\
(\mathrm{NS})\end{array}$ \\
\hline $\begin{array}{l}\text { High pressure area - } \\
\text { Upper part }(\%)\end{array}$ & 56.48 & 62.53 & 2.06 & $\begin{array}{l}=0.0664 \\
(\mathrm{NS})\end{array}$ & 50.23 & 60.74 & 1.74 & $\begin{array}{l}=0.1128 \\
(\mathrm{NS})\end{array}$ \\
\hline $\begin{array}{l}\text { Low pressure area - } \\
\text { Middle part }(\%)\end{array}$ & 51.98 & 43.63 & 1.90 & $\begin{array}{l}=0.0858 \\
(\mathrm{NS})\end{array}$ & 39.82 & 51.39 & 1.34 & $\begin{array}{l}=0.2099 \\
(\mathrm{NS})\end{array}$ \\
\hline $\begin{array}{l}\text { High pressure area - } \\
\text { Middle part }(\%)\end{array}$ & 48.02 & 56.37 & 1.90 & $\begin{array}{l}=0.0862 \\
(\mathrm{NS})\end{array}$ & 60.18 & 48.61 & 1.35 & $\begin{array}{l}=0.2078 \\
(\mathrm{NS})\end{array}$ \\
\hline $\begin{array}{l}\text { Low pressure area - } \\
\text { Lower part }(\%)\end{array}$ & 21.56 & 12.89 & 1.43 & $\begin{array}{l}=0.1843 \\
(\mathrm{NS})\end{array}$ & 13.02 & 22.58 & 1.43 & $\begin{array}{l}=0.1840 \\
(\mathrm{NS})\end{array}$ \\
\hline $\begin{array}{l}\text { High pressure area - } \\
\text { Lower part }(\%)\end{array}$ & 78.44 & 87.11 & 1.43 & $\begin{array}{l}=0.1843 \\
(\mathrm{NS})\end{array}$ & 86.98 & 77.42 & 1.43 & $\begin{array}{l}=0.1840 \\
(\mathrm{NS})\end{array}$ \\
\hline
\end{tabular}


The various changes in the gait parameters, after the intervention, in both the groups are shown in Table 1 and Table 2.

Table 2. Comparison of mean improvement in the gait parameters after the intervention between the two groups

\begin{tabular}{|c|c|c|c|c|}
\hline Parameters & $\begin{array}{c}\text { Mean of } \\
\text { difference - } \\
\text { Group A } \\
\text { (NDT and } \\
\text { Conventional } \\
\text { Physiotherapy) }\end{array}$ & $\begin{array}{c}\text { Mean of } \\
\text { difference - } \\
\text { Group B } \\
\text { (Conventional } \\
\text { Physiotherapy) }\end{array}$ & 总 & $\begin{array}{c}\text { p- } \\
\text { value }\end{array}$ \\
\hline $\begin{array}{l}\text { Step length } \\
\text { affected } \\
(\mathrm{cms})\end{array}$ & 10.45 & 3.73 & 3.94 & $\begin{array}{c}0.0008 \\
(\mathrm{~S})\end{array}$ \\
\hline $\begin{array}{l}\text { Step length } \\
\text { unaffected } \\
\text { (cms) }\end{array}$ & 13.91 & 4.82 & 4.31 & $\begin{array}{c}0.0003 \\
(\mathrm{~S})\end{array}$ \\
\hline $\begin{array}{l}\text { Stride } \\
\text { length } \\
\text { (cms) }\end{array}$ & 24.12 & 6.82 & 5.1 & $\begin{array}{c}\text { 0.0001 } \\
\text { (S) }\end{array}$ \\
\hline Cadence & 20.36 & 12.18 & 1.7 & $\begin{array}{c}\mathbf{0 . 1 0 5 0} \\
\text { (NS) }\end{array}$ \\
\hline $\begin{array}{l}\text { Gait } \\
\text { velocity } \\
(\mathrm{cm} / \mathrm{s})\end{array}$ & 10.51 & 5.45 & 1.51 & $\begin{array}{c}\mathbf{0 . 1 4 7 3} \\
\text { (NS) }\end{array}$ \\
\hline $\begin{array}{l}\text { WGS } \\
\text { Score }\end{array}$ & 8.41 & 4.04 & 2.28 & $\begin{array}{c}\mathbf{0 . 0 3 3 5} \\
(\mathbf{S})\end{array}$ \\
\hline
\end{tabular}

The affected step length (t-value 6.82, $\mathrm{p}$ - value $<0.0001)$, unaffected step length (t-value 7.27, $\mathrm{p}$ - value $<0.0001$ ) as well as stride length (t-value 7.63, p value $<0.0001)$ increased in the group receiving NDT along with conventional physiotherapy (Group A) as well as in the group receiving only conventional physiotherapy (Group B) (Affected Step length t-value 4.25, p -value 0.0017) (Unaffected Step length $\mathrm{t}$ - value 4.78, pvalue 0.0007) (Stride length t-value 4.41, $\mathrm{p}$-value 0.0013). The gait velocity and cadence also improved in the group $\mathrm{A}$ (Gait velocity t-value 3.34, p -value 0.0075) (Cadence t-value 4.56, $\mathrm{p}$-value 0.0010) as well as in Group B (Gait velocity t-value $4.69, \mathrm{p}$-value 0.0009 ) (Cadence t-value 6.08, $\mathrm{p}$-value 0.0001). There also occurred significant improvement in WGS scores in both the groups (Group A t-value 6.44, p -value $<0.0001$ ) (Group B t-value 5.86, p -value
0.0002). But significant reduction in spasticity (MAS-Hip, t-value 3.46, MAS-Knee, $\mathrm{t}$ - value 3.73, MAS-Ankle, t- value 3.73) was only observed in the Group A. However, no statistically significant difference was observed in the high and low pressure areas of upper, middle and lower parts of foot in both the groups after the intervention.

There was a statistically significant difference in the changes in the step length of affected side (t-value 3.94, p value 0.0008 ), step length of unaffected side, (t-value 4.31, p -value 0.0003), stride length ( $\mathrm{t}$-value 5.1, p -value 0.0001 ) and WGS scores (t-value 2.28, p -value 0.0335) between the Groups A and B.

\section{Discussion}

Regaining independent walking ability forms a major goal of all rehabilitation programs and is, indeed, of great significance to patients who have suffered a stroke. Rehabilitation therapy after a stroke is costly and can be justified only if the therapy program is appropriate and if recovery would not occur naturally.

Hemiparetic gait is characterized by slow and asymmetric steps with delayed and disrupted equilibrium reactions and reduced weight bearing on the paretic limb (Perry, 1992, Yavuzer et al, 2001, Yavuzer \& Ergin, 2002). Restoration of normal movements of the trunk, pelvis, and lower extremity, and improved weight bearing on the paretic side while walking, are some of the most important goals of stroke rehabilitation (Roth \& Harvey, 2000). Therefore, the present study was conducted to evaluate the efficacy of two treatment approaches in correction and re-education of gait 
patterns of post stroke hemiparetic patients.

The findings of present study has demonstrated a significant improvement in various gait parameters such as step length of affected side, step length of unaffected side as well as stride length in both the groups $\mathrm{A}$ and $\mathrm{B}$, indicating that both approaches, NDT based gait training in addition to conventional physiotherapy as well as conventional physiotherapy alone, are effective in improving these gait parameters in post stroke hemiparetic patients. This can be attributed to the fact that in both the groups, gait training helped in achieving more weight bearing on the affected side and corrected the asymmetry of steps as well as gait pattern in these patients. The rehabilitation program given to the patients in this study reduced the balance deficiencies and difficulty in moving the body over an unstable limb. The basic reason for short step and stride length in hemiparetic patients is that the patients spend less time on the paretic side as compared to the non paretic side. Therefore in both the groups, the exercises were designed in such a way that the patients were made to spend more time in stance on the paretic side than on the unaffected side. This resulted in the increased step length and stride length in both the groups.

However, the study also reveals that NDT based gait training in addition to a conventional physiotherapy program provides more benefit than a conventional stroke rehabilitation program alone, in improving these gait parameters. These findings could be explained on the basis of concept of NDT that considers "abnormal tone" and "abnormal coordination of movement patterns" to be the main problems of patients with hemiparesis, as both of these problems, were effectively addressed in the present study. This was manifested by statistically significant reduction in spasticity in the hip adductors, knee extensors and ankle plantar flexors in the patients who received NDT based gait training. It is reasonable to believe that this reduction in spasticity or better said, normalizing tone, is the necessary preparation for practicing functional activities such as walking.

To correct the problem of "abnormal coordination of movement patterns", in the NDT group of present study, more emphasis was given on exercises aimed at developing selective motor control, enhancing balance, righting and equilibrium reactions as well as discouraging stereotyped mass movement patterns. Additionally, handling techniques were used to correct alignment, to assist movement that the patient struggles to perform independently, and to block atypical movements. This might have reduced the patient's effort during movement, thus normalizing tone and producing more selective movement as opposed to stereotypical mass patterns.

Thus, facilitation of selective control of movement, achieved by the reeducation of basic movement patterns of the trunk, the pelvis, and the limbs, was a key feature, used in the NDT approach. This probably resulted in more significant improvement in step length and stride length in the group receiving additional NDT. The work done by Davies (2000) further confirms the fact that commonly used rehabilitation programs such as NDT are specifically focused on restoring normal gait with a symmetrical pattern. 
Conversely, there are certain researchers, though limited in number, who did not find any significant effect in correction of gait after application of NDT. For example, the findings of Sheila et al (2006) did not support the hypothesis that the Bobath approach restored more normal movement patterns to the gait cycle (Lennon et al, 2006). Similarly, Hesse \& co-workers found no significant improvement in gait symmetry after an intensive four weeks inpatient rehabilitation program based on a neuro developmental technique (Hesse et al, 1993, Hesse et al, 1994). However, these studies were hampered by small sample size, execution at a single site, and the lack of baseline evaluation. They reported that tone-inhibiting manoeuvres and exercises in sitting and standing dominated therapy sessions, with little time spent on walking practice. On the contrary, gait-specific practice was a key feature of the NDT based gait training described in this study. The reports of many authors support these findings (Carr \& Shepherd, 1994).

Walking velocity was another important characteristic of the gait of hemiparetic patients, that was given due consideration in the present study. It has been reported as a reliable and responsive predictor of functional status. Walking velocity is a preferred outcome parameter for hemiparetic gait research as it is easy and reliable to measure (Richards et al, 1995). Slow walking velocity in hemiparetic patients has been attributed to a lack of selective motor control and poor balance. However, unfortunately, rehabilitation programs do not mainly focus on increasing velocity fearing that it may cause a more abnormal gait pattern and result in safety problems. The findings of the present study have indicated that, after rehabilitation, walking velocity improved in both the groups. Both NDT based gait training as well as conventional physiotherapy, increased the time spent on the affected side and subsequently smoothened the forward progression of the extremity. This might have resulted in the possible improvement in walking velocity after the rehabilitation program in both the groups. This increase in walking velocity can also be attributed to the fact that there occurred improvement in motor control as well as inhibition of abnormal movement patterns and spasticity. Thus, the cumulative effect of increase in step length, stride length, cadence and most importantly motor control resulted in increasing gait velocity of hemiparetic patients. But the comparison between the two groups showed that addition of NDT based gait training to conventional physiotherapy program is equally effective in comparison to conventional physiotherapy program alone, in improving the gait velocity in post stroke hemiparetic patients. These findings are in agreement with Brock et al (2011) who documented short-term benefit for using interventions based on the Bobath concept for improving walking velocity in people with stroke. Improvement in spatiotemporal and weight bearing symmetry of gait provide an important clinical marker of recovery in rehabilitation as they are associated with better motor functioning and functional independence (Hsu et al, 2003, Yang et al, 2005).

It was interesting to observe in the present study that the improvement in the gait pattern was not only limited to quantitative gait parameters. Rather, there occurred statistically significant improvement in the quality of the gait pattern too, which is evident from the 
improvement in WGS scores. The Wisconsin Gait Scale (WGS) is a useful tool to rate qualitative gait alterations of post-stroke hemiplegic subjects and to assess changes over time during rehabilitation training (Pizzi et al, 2007). Although significant improvement was seen in both the groups, but it was evident that NDT based gait training in addition to conventional physiotherapy was more effective in improving the qualitative aspect of the hemiplegic gait in comparison to conventional physiotherapy alone. This can be attributed to the fact that in NDT program, the therapists use their handling techniques to correct alignment, to assist movement that the patient struggles to perform independently, and to block atypical movements. This resulted in the development of more selective motor control. Various exercises in the NDT group resulted in better recovery of movement of the affected side and functional activity.

The findings of present study also suggested that there occurred statistically insignificant difference in low and high pressure areas in the upper, middle and lower parts of the foot in both the groups. It proved that neither NDT based gait training nor conventional physiotherapy has any significant effect on the pressure areas in the various parts of the foot. Although the changes were statistically insignificant, there occurred some increase in the high pressure areas in the upper part of the foot, in both the groups, after the intervention, indicating a positive shift towards the normal values as seen in the healthy adults of same age group. Whereas in the middle and lower part of the foot, the insignificant increase in high pressure areas was only observed in the Group A, receiving NDT based gait training in addition to conventional physiotherapy. In the present study, there were variations in the magnitude of these parameters as reflected by the high standard deviations of the gait parameters and these variations may be due to the wide variability of gait after stroke. Further exploratory work of this nature is needed to arrive at a consensus on the changes occurring in the pressure areas of the foot in post stroke hemiparetic patiens.

In conclusion, addition of NDT based gait training is more effective in gait correction and re-education of gait of post stroke hemiparetic patients. NDT further helps in normalizing the gait pattern and as well as increasing the symmetry of gait in these patients.

\section{References:}

1. American Heart Association. Heart and Stroke Disease Statistics-2003 update. www.americanheart.org

2. DeJong, G., Horn, S.D., Conroy, B., Nichols, D., Healton, E.B. 2005. Opening the Black Box of Post stroke Rehabilitation: Stroke Rehabilitation Patients, Processes, and Outcomes. Archv. Physic. Med. Rehab., 86 (12 Suppl): 1-7.

3. Hankey, G.J. 1999. Stroke. How large a public health problem and how can the neurologist help? Archv. Neurol., 56: 748754.

4. Weir, N.U., Sandercock, D.M., Lewis, S.C., Signorini, D.F., Warlow, C.P. 2001. Variations between countries in outcome after stroke in the International Stroke Trial (IST). Stroke, 32: 1370-77.

5. Akhan, G., Kalkan, E., Cyrak, P., Pahin, B. 1995. The epidemiology of stroke in Isparta: 1990-1993. In Neurology and Public Health. Eds Kyrbap D, Leonardi M. Bitam Publications. 115-20.

6. Skilbeck, C.E., Wade, D.T., Hewer, R.L., Wood, V.A. 1983. Recovery after stroke. $J$ Neurol. Neurosurg. Psychiatry; 46: 5-8. 
7. Jorgenson, H.S., Nakayama, H., Raaschau, H.O., Olsen, T.S. 1995. Recovery of walking function in stroke patients: the Copenhagen Stroke Study. Arch. Phys. Med. Rehabil., 76: 27-32.

8. Skilbeck, C.E., Wade, D.T., Hewer, R.L., Wood, V.A. 1983. Recovery after stroke. J. Neurol. Neurosurg. Psychiatry, 46(1): 5-8.

9. Winter, D.A., Patla, A.E., Frank, J.S., Walt, S.E. 1990. Biomechanical walking patterns changes in the fit and healthy elderly. Phys. Ther., 70: 340-347.

10. Olney, S.J., Richards, C. 1996. Hemiparetic gait following stroke, part 1: characteristics. Gait \& Posture, 4: 136-148.

11. Moseley, A., Wales, A., Herbert, R., et al. 1993. Observation and analysis of hemiplegic gait: stance phase. Aust. J. Physioth, 39: 259 $-267$.

12. Moore, A., Schurr, K., Wales, A., et al. 1993. Observation and analysis of hemiplegic gait: swing phase. Aust. J. Physioth, 39: 272- 278.

13. De Quervain, I.A., Simon, S.R., Leurgens. S, et al. 1996. Gait pattern in the early recovery period after stroke. J. Bone Joint Surg Am, 78: $1506-1514$.

14. Paci, M. 2003. Physiotherapy based on the Bobath concept for adults with post-stroke hemiplegia: A review of effectiveness studies. J. Rehabil. Med., 35: 2-7.

15. Ashburn, A., Partridge, C., De Souza, L. 1993. Physiotherapy in the rehabilitation of stroke: a review. Clin. Rehab., 7: 337-345.

16. Perry, J. 1992. Gait analysis: Normal and pathological function. Thorofare (NJ): Slack; 224-226.

17. Yavuzer, G., Ergin, S. 2002. Effect of Arm Sling on Gait Pattern in Patients with Hemiplegia. Arch. Phys. Med. Rehab., 83: 960-963.

18. Yavuzer, G., Gök, H., Ergin, S. 2001. Spatiotemporal and kinematic gait characteristics of stroke patients. The $J$. Rheumat. Med. Rehab., 12: 148-152.

19. Roth, E.J., Harvey, R.L. 2000. Rehabilitation of stroke syndromes. In: Braddom RL, ed. Physical Medicine and Rehabilitation 2nd ed. Philadelphia, Pa: WB Saunders, 1117-63.

20. Davies, P.M., 2000. Steps to follow - the comprehensive treatment of patients with hemiplegia. $\quad$ Springer-Verlag: Berlin Heidelberg.

21. Sheila, L., Ann, A. and Baxter, D. 2006. Gait outcome following outpatient physiotherapy based on the Bobath concept in people post stroke. Disabil Rehabil., 28(13-14): 873-81

22. Hesse, S.A., Jahnke, M.T., Schreiner, C., Mauritz, K.H. 1993. Gait symmetry and functional walking in hemiparetic patients prior to and after a 4-week rehabilitation programme. Gait \& Posture, 1: $166-171$.

23. Hesse, S.A., Jahnke, M.T., Bertelt, C.M., et al. 1994. Gait outcome in ambulatory hemiparetic patients after a 4-week comprehensive rehabilitation program and prognostic factors. Stroke, 25: $1999-2004$.

24. Carr, J.H., Shepherd, R.B. 1998. Neurological Rehabilitation: Optimising Motor Performance. Oxford, England: Butterworth-Heinemann.

25. Richards, C.L., Malouin, F., Dumas, F., Tardif, D. 1995. Gait velocity as an outcome measure of locomotor recovery after stroke. In: Craig, R., Oatis, C., editors. Gait analysis: theory and applications. St. Louis:Mosby, p. 355-64.

26. Brock, K., Haase, G., Rothacher, G., Cotton, S. 2011. Does physiotherapy based on the Bobath concept, in conjunction with a task practice, achieve greater improvement in walking ability in people with stroke compared to physiotherapy focused on structured task practice alone?: a pilot randomized controlled trial. Clin. Rehabil. Oct; 25(10): 903-12.

27. Yang, Y.R., Yen, J.G., Wang, R.Y., Yen, L.L., Lieu, F.K. 2005. Gait outcomes after additional backward walking training in patients with stroke: a randomized controlled trial. Clin. Rehabil., 19: 264-73.

28. Hsu, A.L., Tang, P.F., Jan, M.H. 2003. Analysis of impairments influencing gait velocity and asymmetry of hemiplegic patients after mild to moderate stroke. Arch. Phys. Med. Rehabil., 84: 1185-93.

29. Pizzi, A., Carlucci, G., Falsini, C., Lunghi, F., Verdesca, S., Grippo, A. 2007. Gait in hemiplegia: evaluation of clinical features with the Wisconsin Gait Scale. J. Rehabil. Med., 39(2): 170-4. 